\title{
Seronegative autoimmune encephalitis
}

\author{
Owais Alsrouji MD, Anza B. Memon MD
}

Cite as: CMAJ 2020 November 30;192:E1638. doi: 10.1503/cmaj.200424

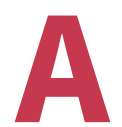

68-year-old woman with a history of rheumatoid arthritis presented to the emergency department with 3 months of rapidly progressing cognitive decline. Examination revealed new short-term memory loss, poor attention, difficulty conceptualizing tasks and inability to complete multistep actions. Three days after admission, the patient developed limb rigidity, hyperreflexia, exaggerated startle response, and autonomic dysfunction with fluctuations in blood pressure and heart rate.

Magnetic resonance imaging (MRI) of the patient's brain showed bilateral confluent hyperintense signal changes in the basal ganglia (Figure 1A). Autoimmune serology revealed positive antinuclear antibody at 1:640 (homogenous pattern; reference range $<1: 80$ ) and elevated cyclic citrullinated peptide antibody (> $340 \mathrm{IU} / \mathrm{mL}$ [reference range $<7 \mathrm{IU} / \mathrm{mL}]$ ). Consistent with a diagnosis of seronegative autoimmune encephalitis, serology was negative for glutamic acid decarboxylase, $\mathrm{N}$-methyl-D-aspartate receptor and glycine receptor antibodies. Cerebrospinal fluid analysis revealed only an elevated protein level of $203 \mathrm{mg} / \mathrm{dL}$ (normal range 15-55 mg/dL). Further long-chain fatty acid, toxic, infectious and neoplastic test results were negative (Appendix 1, available at www.cmaj.ca/lookup/ doi/10.1503/cmaj.200424/tab-related-content), and we diagnosed the patient with autoimmune encephalitis.

The patient received a $1 \mathrm{~g}$ dose of methylprednisolone, after which gastrointestinal bleeding developed. Two weeks later, a repeat brain MRI showed interval worsening of findings (Figure 1B). She was treated with 5 rounds of plasmapheresis, after which a repeat brain MRI showed nearly complete resolution of basal ganglia hyperintensity (Figure $1 \mathrm{C}$ ). She received rituximab, and 6 weeks later she had made a full neurologic recovery.

Autoimmune encephalitis has an incidence of 5-10 per 100000 person-years. ${ }^{1}$ Diagnosis is based on the clinical presentation of progressive encephalomyelitis and neuroimaging findings suggestive of encephalitis. ${ }^{1,2}$ Negative antibody test results do not exclude autoimmune encephalitis, and there is an
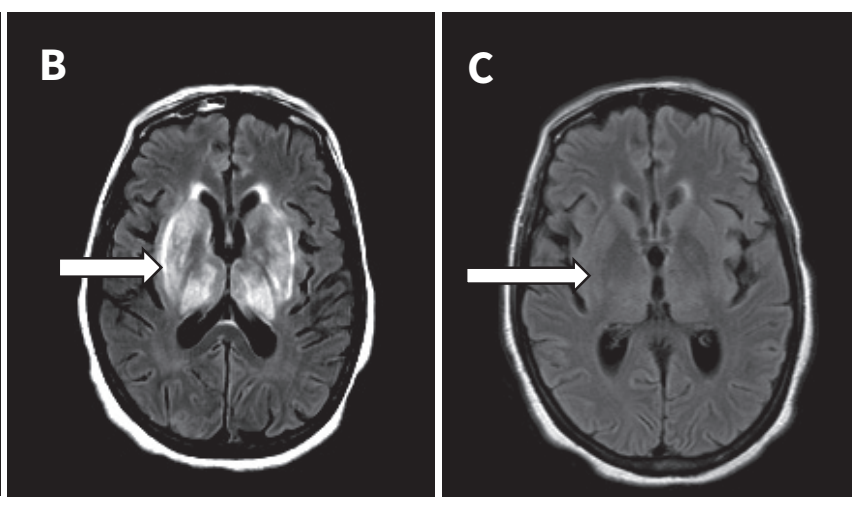

Figure 1: Magnetic resonance imaging (MRI) of the brain of a 68-year-old woman with autoimmune encephalitis. (A) Initial brain MRI revealed bilateral confluent hyperintense signal changes in thalami, caudate and (arrow). (B) Repeat brain MR 列 ganglia (arrow). (C) Repeat brain MRI 8 days postplasmapheresis showed nearly complete resolution of the confluent basal ganglia hyperintensity (arrow).

increased risk of morbidity and death in untreated patients. ${ }^{2}$ Timely diagnosis and intervention, including immunomodulatory therapies such as intravenous immunoglobulin, high-dose corticosteroids and plasmapheresis, are associated with good outcomes. Patients with an aggressive or relapsing course require maintenance therapy with immunosuppressants.

\section{References}

1. Graus F, Titulaer MJ, Balu R, et al. A clinical approach to the diagnosis of autoimmune encephalitis. Lancet Neurol 2016;15:391-404.

2. Dutra LA, Abrantes F, Toso FF, et al. Autoimmune encephalitis: a review of diagnosis and treatment. Arq Neuropsiquiatr 2018;76:41-9.

\section{Competing interests: None declared.}

This article has been peer reviewed.

The authors have obtained patient consent.

Affiliations: Department of Neurology (Alsrouji, Memon), Henry Ford Hospital; Wayne State University (Memon), School of Medicine, Detroit, Mich.

Acknowledgement: The authors thank Stephanie Stebens for her assistance with this manuscript.

Correspondence to: Anza Memon, amemon2@hfhs.org 